American Journal of Applied Sciences 6 (1): 133-136, 2009

ISSN 1546-9239

(C) 2009 Science Publications

\title{
Effect of Evaporator Section Lengths and Working Fluids on Operational Limit of Closed Loop Oscillating Heat Pipes with Check Valves (CLOHP/CV)
}

\author{
${ }^{1} \mathrm{P}$. Meena, ${ }^{2} \mathrm{~S}$. Rittidech and ${ }^{3} \mathrm{P}$. Tammasaeng \\ ${ }^{1,3}$ Faculty of Science, \\ ${ }^{2}$ Faculty of Engineering, \\ Mahasarakham University, Thailand, 44150
}

\begin{abstract}
This research aims to the effect of evaporator section lengths and working fluids on operational limit of closed loop oscillating heat pipes with check valves (CLOHP/CV) with R123 Ethanol and Water were used as the working fluids. A set of CLOHP/CV was made of copper tubes in combination of following dimension: $1.77 \mathrm{~mm}$ inside diameter: 10 turns: 5, 10 and $15 \mathrm{~cm}$ equal lengths for evaporator, adiabatic and condenser sections. The working fluid was filled in the tube at the filling ratio of 50\%. The evaporator section was given heat by heater while the condenser section was cooled by volume water in a cold bath. The adiabatic section was properly insulated. In the test operation. Which the temperature at the adiabatic section was controlled at $60^{\circ} \mathrm{C}$ in steady-state condition. From The obtained results obtained, it could be concluded as follows. When the evaporator lengths increased from $5 \mathrm{~cm}$ to 10 and $15 \mathrm{~cm}$ the critical heat transfer flux decreased. There was working fluids change from R123 to Ethanol and water the critical heat flux decreased.
\end{abstract}

Key words: Closed-looped oscillating heat-pipe, check valves, operational limit, critical heat flux

\section{INTRODUCTION}

The CLOHP/CV is a very effective heat transfer device Akachi et al. ${ }^{[1]}$ : it has a simple structure and fast thermal- response. The CLOHP/CV consists of a long capillary tube bent into many turns and the evaporator section, adiabatic section and condenser section are located at these turns, with the ends joined to form a closed loop. It incorporates one or more directioncontrol one-way check valves in the loop so that the working fluid can circulate in specified direction only. Miyazaki et al ${ }^{[2]}$ : studies the oscillating heat-pipe with check valves. It was found that the $\mathrm{CHOHP} / \mathrm{CV}$, as a high efficiency heat transfer. Pipatpaiboon et al. ${ }^{[3]}$ : studies the effect of inclination angle working fluid and number of check vales on the characteristics of heat transfer in a closed-looped oscillating heat-pipe with check valves (CLOHP/CV). It was found that the $\mathrm{CHOHP} / \mathrm{CV}$ is equipped with 2 check valves, as highest heat transfer. Rittidech et al. ${ }^{[4]}$ : studies the correlation to predict heat transfer of a closed-looped oscillating heat-pipe with check valves (CLOHP/CV). Meena et al. ${ }^{[5]}$ : studies the application of closed-loop oscillating heat-pipe with check valves (CLOHP/CV) air-preheater for reduced relative-humidity in drying systems. It was found that the (CLOHP/CV) airpreheater can be reduced relative humidity in a drying system. Rittidech et al. ${ }^{[6]}$ : studies the effect of evaporator lengths and ratio of check valves to number of turns on internal flow patterns of a closed-loop oscillating heat pipe with check valves. It was found that the $\mathrm{CHOHP} / \mathrm{CV}$ is equipped with Rcv 0.2 , as highest heat transfer.

The principle of operation is similar to that of the CLOHP/CV are widely accepted as the most efficient heat transfer device for high heat load Akachi et al. ${ }^{[1]}$. Because it incorporates one or more direction-control one-way check valves in the loop so that the working fluid can circulate in specified direction only in shown (Fig. 1a,b).

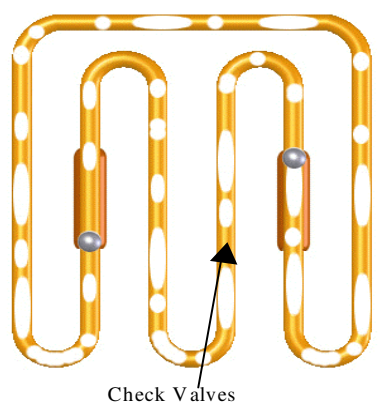

Fig. 1a: Closed-looped oscillating heat-pipe with check valves (CLOHP/CV) 


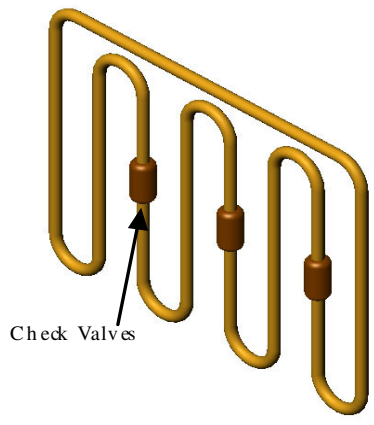

Fig. 1b: Closed-looped oscillating heat-pipe with check valves (CLOHP/CV)
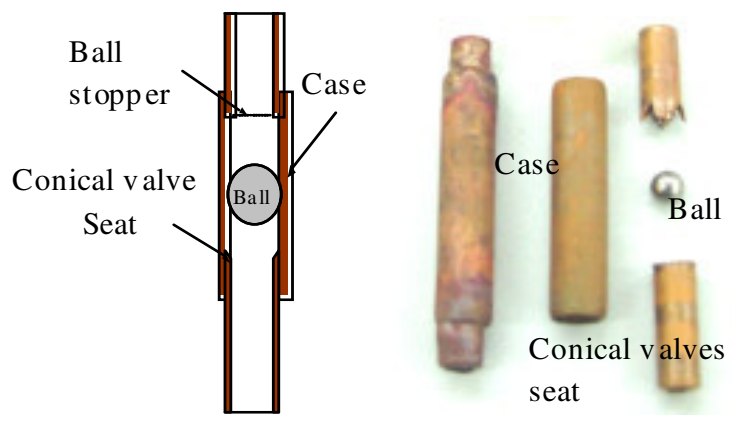

Fig. 2: The check valve

The objectives to experimentally investigate the following aspects of effect of evaporator section lengths and working fluids on operational limit of closed loop oscillating heat pipes with check valves (CLOHP/CV):

- To study the effect of evaporator section lengths on operational limit of closed loop oscillating heat pipes with check valves

- To study the effect of working fluids properties on the operational limit of closed loop oscillating heat pipes with check valves

\section{THE CHECK VALVES}

The check valve is a floating type valve that consists of a stainless ball and copper tube, in which ball stopper and conical valves seat are provided at the ends, respectively. The ball can move freely between the ball stopper and the valves seat in shown Fig. 2 .

\section{MATERIALS AND METHODS}

Test rig: The CLOHP/CV was made of copper tube. with R123 Ethanol and Water were used as the working fluids. A set of CLOHP/CV was made of copper tubes

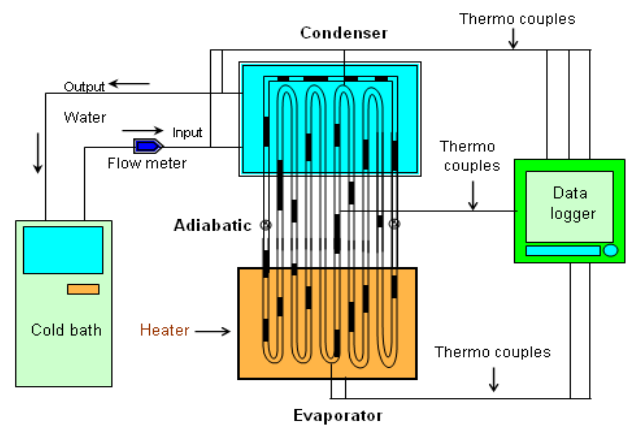

Fig. 3: Test rig

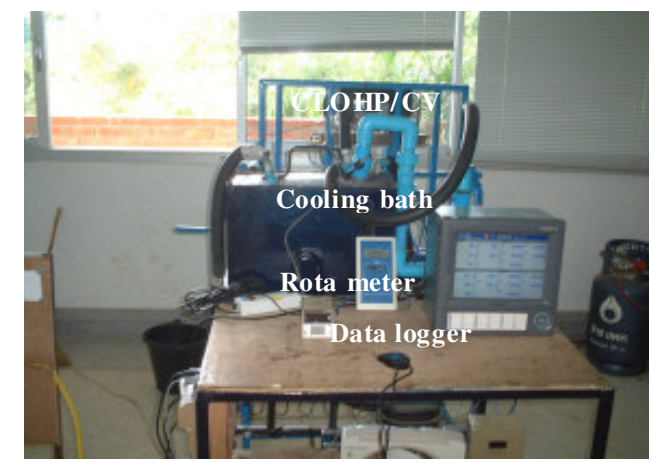

Fig. 4: The prototype experimental setup

in combination of following dimensions: 1.77 inside diameter: 10 turns: 5,10 and $15 \mathrm{~cm}$ equal lengths for evaporator, adiabatic and condenser sections. The working fluid was filled in the tube at the filling ratio of 50\% in shown Fig. 3.

Figure 3, 4 shows an experimental setup which consists of a CLOHP/CV with a heating bath for the evaporator section and a cooling bath for the condenser section. The adiabatic section was properly insulated.

In the test operation the temperature at the adiabatic section was controlled at $60^{\circ} \mathrm{C}$ in steady-state condition. The data logger Yokogawa-MX100 was used with type $K$ thermocouples (Omega with $\pm 1^{\circ} \mathrm{C}$ accuracy) attached to the inlet and outlet of the cooling jacket, thermocouples were attached to the outside surface wall of the CLOHP/CV and data were recorded. These were 3 points on the evaporator, 2 points on the condenser and 2 points on the adiabatic section. The evaporator section was given heat by heater while the cold bath was used to pump the cooling substance into the cooling jacket and the floating. Rota meter (Platon PGB411) was used to measure the flow rate of the cooling medium. They were used to calculate the heat transfer of the test CLOHP/CV by using the calorific method, as the following Eq: 


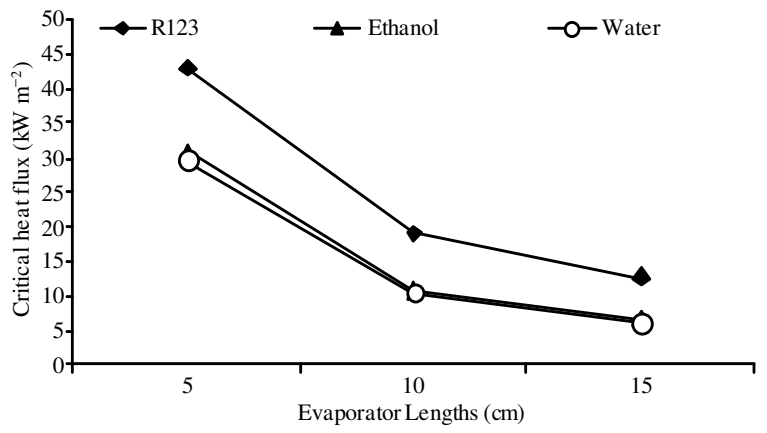

Fig. 5: Evaporator lengths and critical heat flux

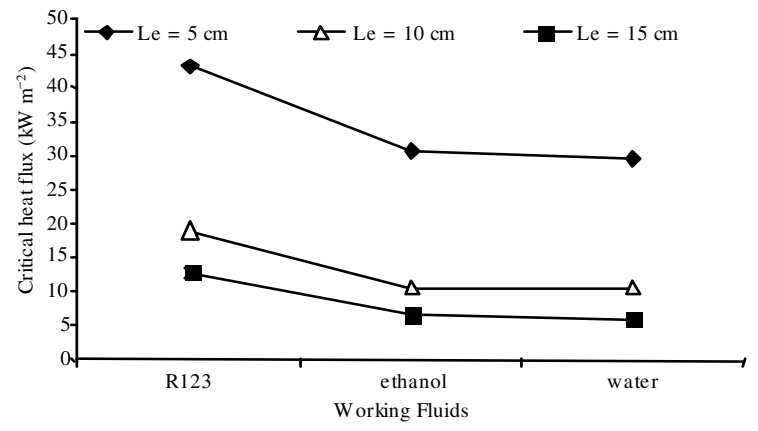

Fig. 6: Working fluids and critical heat flux

and

$$
\mathrm{Q}=\mathrm{m}^{\bullet} \mathrm{c}_{\mathrm{p}}\left(\mathrm{T}_{\text {out }}-\mathrm{T}_{\mathrm{in}}\right)
$$

\section{Variable parameters were:}

- Evaporator section lengths of 510 and $15 \mathrm{~cm}$

- Working fluid of R123, ethanol and water (since their boiling pressures are acceptable for the required temperature range and their latent heat of vaporization are totally different)

- $\quad$ Inner diameters of the tubes was 1.77

\section{RESULT AND DISCUSSION}

Effect of evaporator section lengths to critical heat flux: Figure 5 shows the relationship of evaporator section lengths to the critical heat flux of the CLOHP/CV. It can be observed that, the evaporator section lengths affect the critical heat flux such that the longer evaporator section lengths, these results of the effect of evaporator section lengths can be found that the value of maximum critical heat flux of evaporator section lengths was 510 and $15 \mathrm{~cm}$ for R123 ethanol and water respectively.

Effect of working to critical heat flux: Figure 6 shows the relationship between working fluids of the
CLOHP/CV and critical heat flux. It can be seen that, the latent heat of vaporization affects the critical heat flux. The working fluid with a lower latent heat of vaporization exhibits the higher critical heat flux as the following; the values of maximum critical heat flux for $\mathrm{R} 123$, ethanol and water respectively.

\section{CONCLUSIONS}

- The evaporator section lengths affected on critical heat flux in this range. When the evaporator section lengths increased the critical heat transfer flux decreased

- The latent heat of vaporization affects the critical heat flux. The working fluid with the lower latent heat of vaporization exhibits a higher critical heat flux

\section{ACKNOWLEDGEMENTS}

The research has been supported generously by Mahasarakham University, Thailand. The authors express their sincere appreciation for all of the support provided.

\section{NOMENCLATURE}

$\mathrm{m}^{\bullet}=$ Mass per unit time

$\mathrm{C}_{\mathrm{p}}=$ Specific heat capacity, constant pressure

$\mathrm{T}_{\text {out }}=$ Outlet temperature at condenser section

$\mathrm{T}_{\mathrm{in}}=$ Inlet temperature at condenser section

$\mathrm{T}_{\text {evap }}=$ Temperature at evaporator section

$\mathrm{T}_{\text {cond }}=$ Temperature at condenser section

\section{REFERENCES}

1. Akachi, H., F. Polasek and P. Stulc, 1996. Pulsating heat pipe. Proceeding of the 5th International Heat Pipe Symposium, Melbourne Australia, pp: 208-217.

2. Miyazaki, Y., F. Polasek and H. Akachi, 2000. Oscillating heat pipe witch check valves. Proceeding of the 6th International Heat Pipe Symposium, Chiang Mai, Thailand, pp: 389-393.

3. Pipatpaiboon, N., S. Rittidech and T. Sukna P. Suddee, 2004. Effect of inclination angle working fluid and number of check valves on the characteristics of heat transfer in a closed-looped oscillating heat-pipe with check valves (CLOHP/CV). Proceeding of 1st International Seminar on Heat Pipe and Heat Recovery Systems, Kuala Lumpur, Malaysia, pp: 83-87. 
4. Rittidech, S., N. Pipatpaiboon and P. Terdtoon, 2007. Heat-transfer characteristics of a closedlooped oscillating heat pipe with check valves. Applied Energy, 84: 565-577.

5. Meena, P., S. Rittidech and N. Poomsa-ad, 2007. Application of close-looped oscillating heat-pipe with check valves (CLOHP/CVs) air-preheater for reduced relative-humidity in drying systems. Applied Energy, 84: 553-564.
6. Rittidech, S., P. Meena and P. Terdtoon, 2008. Effect of evaporator lengths and ratio of check valves to number of turns on internal flow patterns of a closed-loop oscillating heat pipe with check valves. Am. J. Applied Sci., 5: 184-188. 